\title{
Transluminal angioplasty for arteriosclerotic disease of the distal vertebral and basilar arteries
}

Tomoaki Terada, Randall T Higashida, Van V Halbach, Christopher F Dowd, Ekina Nakai, Hideyuki Yokote, Toru Itakura, Grant B Hieshima

\begin{abstract}
Objective-Percutaneous transluminal angioplasty (PTA) for the distal vertebral and basilar artery is now being performed in selected patients with haemodynamically significant lesions of the posterior cerebral circulation. Its effect and overall results were examined.
\end{abstract}

Patients and methods-A balloon dilatation catheter specifically developed for these procedures, with a $2 \cdot 0-3 \cdot 5 \mathrm{~mm}$ balloon diameter, at 6 atmospheres of pressure, was used. Angioplasty was performed in 12 patients (including six whose initial results have been reported) with angiographically documented stenotic lesions involving either the intracranial vertebral artery (C1-C2 portion) or the basilar artery, and satisfying the following criteria: (1) clinical symptoms suggestive or consistent with a transient ischaemic attack refractory to medical treatment, or small infarction of the posterior circulation; and (2) angiographically documented stenosis greater than $70 \%$. Two of 12 patients had complete thrombosis of the distal vertebral and basilar artery and PTA was performed after successful intra-arterial thrombolysis.

Department of

Neurological Surgery,

Wakayama Medical

University, Wakayama

City, Japan

$T$ Terada

E Nakai

H Yokote

T Itakura

Department of

Radiology and

Neurological Surgery,

Interventional

Neurovascular

Radiology Division,

University of

California San

Francisco Medical

Center, San Francisco,

CA, 94143-0628 USA

R T Higashida

V V Halbach

C F Dowd

G B Hieshima

Correspondence to:

Dr Tomoaki Terada,

Departmentof Neurological

Surgery, Wakayama Medical

College, 7 ban-cho 27

Wakayama City 640, Japan.

Received 18 May 1995

and in final revised form

11 December 1995

Accepted 16 December 1995 nent neurological deficits. The two patients with thromboembolic complication showed transient neurological deficit. The overall stenosis ratio decreased from a mean of $84 \%$ pretreatment to $44 \%$ after the angioplasty procedure. Restenosis occurred in two patients. Long term clinical follow up in 11 patients who survived more than six months showed resolution of ischaemic symptoms after PTA in all except for one with a restenosis who had recurrent transient ischaemic attacks. Conclusion-Transluminal angioplasty may be an effective procedure to treat vertebrobasilar ischaemia secondary to high grade arteriosclerotic disease affecting either the distal vertebral or basilar artery regions that do not respond to medical treatment.

\section{$(\Im$ Neurol Neurosurg Psychiatry 1996;60:377-381)}

Keywords: arteriosclerosis; basilar artery; cerebral infarction; percutaneous transluminal angioplasty; vetebral artery

Acute occlusion of either the basilar artery or both vertebral arteries usually results in severe neurological deficits. ${ }^{1-3}$ Surgical revascularisation involving the posterior cerebral circulation is more difficult compared with revascularisation of the anterior circulation. ${ }^{4-6}$

In 1980 , Sundt et $a l,{ }^{7}$ reported the first successful treatment of basilar artery arteriosclerotic stenosis by intraoperative percutaneous transluminal angioplasty (PTA). However, the technique of PTA for the intracranial vertebrobasilar system has not developed rapidly compared with that of the coronary, peripheral, and extracranial arteries. ${ }^{8-10}$ This is due to the potential risk of vertebrobasilar thromboembolism and the difficulty of navigating the balloon catheter through the tortuous intracranial vessels.

Recent advances in interventional neuroradiology, especially for the microballoon angioplasty catheter, have now made PTA for intracranial arteries possible. ${ }^{811-13}$ We have performed PTA in 12 patients with distal vertebral and/or basilar artery high grade arteriosclerotic disease (including six whose initial results have been reported ${ }^{12}$ ). This paper discusses the technical strategies, feasibility, results, and long term angiographic and clinical outcome for this group of patients.

\section{Materials and methods}

PATIENT SELECTION

Percutaneous transluminal angioplasty was performed in 12 patients with angiographically documented stenosis involving either the distal vertebral artery at the C1-C2 segment or basilar artery region and who satisfied the following criteria: (1) they were clinically symptomatic with vertebrobasilar ischaemic symptoms or small infarction involving the posterior circulation; (2) they had a haemodynamically significant, angiographically documented stenosis of 
greater than $70 \%$ due to atherosclerosis; and (3) they were refractory to standard medical treatment including antiplatelet therapy, anticoagulation therapy, or both.

In patients who had transient ischaemic attacks in the vertebrobasilar distribution, aspirin $(325 \mathrm{mg} /$ day $)$ or ticlopidine $(200$ $\mathrm{mg} /$ day) was given for antiplatelet therapy for at least two to three months before all procedures and continued for six months after angioplasty. If the transient ischaemic attacks seemed refractory to antiplatelet therapy, oral warfarin was given, until the clotting times (prothrombin time) attained were between 1.5 and twofold that of the normal baseline value before angioplasty, and if residual stenosis, significant intimal dissection, or pronounced irregularity of the vessel was seen after angioplasty, patients were given warfarin for six to eight weeks and a repeat angiogram was performed. Patients who presented with either a CT or MRI showing a large area of infarction $(>2.5 \mathrm{~cm})$ were excluded, as revascularisation might induce areas of haemorrhage in a previous site of acute infarction. Patients with small focal areas of infarction were treated medically until the infarction stabilised and then they were treated by angioplasty.

Three patients had transient ischaemic attacks in the vertebrobasilar distribution and eight had small infarctions involving the posterior circulation. One patient had both a transient ischaemic attack in the vertebrobasilar distribution and an acute infarction. Two patients had acute thrombotic occlusion of the distal vertebral and/or basilar artery territory and were treated initially with intra-arterial thrombolysis before balloon angioplasty.

In this series, there were 11 males and 1 female patient. Patient's ranged from 50 to 74 years in age. Seven patients had hypertension and five had diabetes. Four patients had basilar artery stenosis and seven had distal intracranial vertebral artery stenosis. One patient had both vertebral and basilar artery stenosis. All vertebral stenosis were associated with contralateral vertebral occlusion or hypoplasia. The table summarises the clinical presentation of these patients. The initial results for six patients $(1,2,3,5,7,10)$ have already been reported. ${ }^{12}$
The degree of stenosis was measured on an anteroposterior or lateral view according to the North American Symptomatic Carotid Endarterectomy Trial (NACET) criteria. ${ }^{14}$

\section{ENDOVASCULAR TECHNIOUE}

A transfemoral approach was performed in all cases under local anaesthesia. The balloon diameter was determined by measuring the normal calibre of the vessel both above and below the site of stenosis. The diameter of the balloon chosen approximated to but did not exceed the normal luminal diameter for fear of causing overdistension and vessel rupture. An over the wire PTA microballoon system was used, and the balloon diameters ranged from 2.0 to $3.5 \mathrm{~mm}$ (Target Therapeutics Inc, Fremont, CA, USA).

During the procedure, systemic anticoagulation was achieved by giving intravenous heparin $70 \mathrm{U} / \mathrm{kg}$ ) and confirmed with an activated clotting time ( 1.5 to twofold the baseline value). Before the angioplasty, a diagnostic catheter was guided proximal to the site of stenosis, and an angiographic "road map" was obtained to aid in navigating the balloon across the site of stenosis. This map displays the vascular anatomy on the fluoroscopic monitor and simultaneously allows real time fluoroscopy over the image. The monoluminal PTA balloon catheter was passed across the lesion over an 0.016 inch guide wire. The guide wire was then exchanged for a "valve wire" to seal the angioplasty balloon and the balloon was inflated to six atmospheres for 10-20 seconds.

EVALUATION BEFORE AND AFTER ANGIOPLASTY After the angioplasty procedure, arteriography was performed in all patients to assess the degree of dilatation, to evaluate intimal and medial damage, and to view the distal intracranial circulation for evidence of distal embolisation and branch occlusions. Careful evaluation was performed in the neurological observation unit before, immediately after, and then for 24 to 48 hours after the procedure. If the patients' condition was stable they were discharged home and received aspirin, dipyridamole, and/or ticlopidine for at least six months. Patients were followed up clinically at one

Profile of patients who had PTA

\begin{tabular}{|c|c|c|c|c|c|c|c|c|}
\hline $\begin{array}{l}\text { Patient } \\
\text { No }\end{array}$ & Age/sex & Diagnosis & Vascular lesions & $\begin{array}{l}\text { Stenosis } \\
\text { rate (pre-post) }\end{array}$ & $\begin{array}{l}\text { Clinical signs } \\
\text { after PTA }\end{array}$ & $\begin{array}{l}\text { Compli- } \\
\text { cation }\end{array}$ & $\begin{array}{l}\text { Follow up } \\
\text { angiography }\end{array}$ & $\begin{array}{l}\text { Follow up } \\
\text { period and } \\
\text { new symptoms }\end{array}$ \\
\hline $\begin{array}{l}1 \\
2 \\
3 \\
4\end{array}$ & $\begin{array}{l}\text { 69/M } \\
57 / M \\
54 / M \\
59 / M\end{array}$ & $\begin{array}{l}\text { Cerebellar infarct } \\
\text { TIA, infarct } \\
\text { BS infarct } \\
\text { TIA }\end{array}$ & $\begin{array}{l}\text { lt-VA stenosis, rt-VAO } \\
\text { rt-VA stenosis, lt-VAO } \\
\text { rt-VA stenosis, lt-VAO } \\
\text { lt-VA-BA thrombosis } \\
\text { (PTA after thrombolysis) }\end{array}$ & $\begin{array}{l}95 \%-21 \% \\
70 \%-20 \% \\
90 \%-60 \% \\
90 \%-50 \%\end{array}$ & $\begin{array}{l}\text { Not changed } \\
\text { Not changed } \\
\text { Transient deficit } \\
\text { Not changed }\end{array}$ & $\begin{array}{l}0 \\
0 \\
(+) \text { emb } \\
0\end{array}$ & $\begin{array}{l}2 \text { months, restenosis (-) } \\
3 \text { months, restenosis }(-) \\
\text { Not done } \\
\text { Not done }\end{array}$ & $\begin{array}{l}2.5 \text { y None } \\
2 \text { y None } \\
4 \text { y None } \\
1.5 \text { y None }\end{array}$ \\
\hline $\begin{array}{r}5 \\
6 \\
7 \\
8 \\
9 \\
10 \\
11\end{array}$ & $\begin{array}{l}\text { 66/M } \\
72 / \mathrm{M} \\
52 / \mathrm{M} \\
50 / \mathrm{M} \\
60 / \mathrm{M} \\
74 / \mathrm{F} \\
66 / \mathrm{M}\end{array}$ & $\begin{array}{l}\text { BS infarct } \\
\text { Occipital infarct } \\
\text { BS infarct } \\
\text { TIA } \\
\text { TIA } \\
\text { Occipital infarct } \\
\text { BS infarct }\end{array}$ & $\begin{array}{l}\text { lt-VBJ stenosis, rt-VAO } \\
\text { lt-VA stenosis, rt-VAO } \\
\text { BA stenosis } \\
\text { BA stenosis } \\
\text { BA stenosis } \\
\text { rt-VA stenosis, lt-VAO } \\
\text { rt-VA stenosis, lt-VAO }\end{array}$ & $\begin{array}{l}90 \%-40 \% \\
75 \%-40 \% \\
70 \%-60 \% \\
90 \%-40 \% \\
90 \%-50 \% \\
80 \%-70 \% \\
80 \%-60 \%\end{array}$ & $\begin{array}{l}\text { Transient deficit } \\
\text { Permanent deficit } \\
\text { Not changed } \\
\text { Not changed } \\
\text { Not changed } \\
\text { Permanent deficit } \\
\text { Not changed }\end{array}$ & $\begin{array}{l}(+) \text { emb } \\
(+) \text { dis } \\
0 \\
0 \\
0 \\
(+) \text { dis } \\
0\end{array}$ & $\begin{array}{l}2 \text { months, restenosis }(-) \\
\text { Not done } \\
1.5 \text { months, restenosis }(-) \\
\text { Not done } \\
6 \text { months, restenosis }(+) \\
\text { Not done } \\
6 \text { months, restenosis }(+) \\
\text { 2nd PTA }\end{array}$ & $\begin{array}{l}1 \cdot 7 \text { y None } \\
1 \text { y None } \\
4 \text { y None } \\
1.2 \text { y None } \\
1.2 \text { y TIA (+) } \\
\text { Died BS infarct } \\
1.4 \text { y None }\end{array}$ \\
\hline 12 & $61 / \mathrm{M}$ & BS infarct & $\begin{array}{l}\text { BA thrombosis } \\
\text { (PTA after thrombolysis) }\end{array}$ & $90 \%-50 \%$ & Improved & 0 & 1 month, restenosis $(-)$ & 1.4 y None \\
\hline
\end{tabular}

$\mathrm{VA}=$ vertebral artery; $\mathrm{VAO}=$ vertebral artery occlusion; $\mathrm{BA}=$ basilar artery; $\mathrm{VBJ}=$ vertebrobasilar junction; emb = embolic complication; dis = dissection; $\mathrm{TIA}=$ transient ischaemic attack; BS = brain stem 
Figure 1 Angiogram of patient 5. (A) Left vertebral angiogram, anteroposterior view; a high grade stenosis is seen in the distal left vertebral artery at the C1 level (arrow).

(B) Follow up angiogram two months after the initial $P T A$; the stenotic portion is now widely patent.

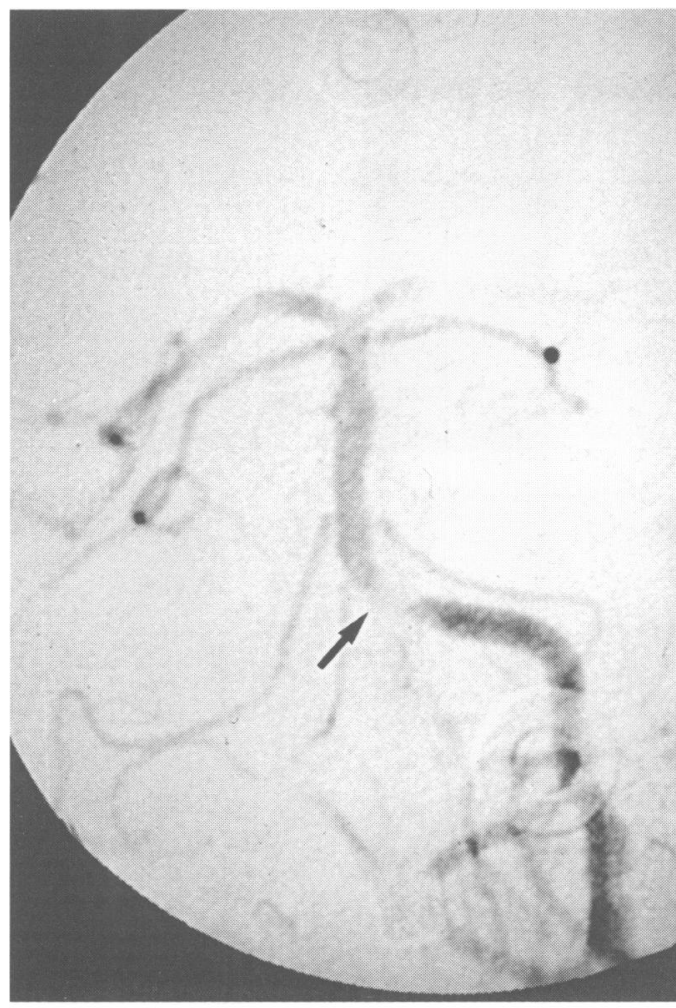

A

to three months and six to 12 months after the procedure. Follow up angiography was scheduled for all patients between one and six months after PTA, if consent was obtained.

\section{Results}

The table summarises our results, complications, and follow up. The average change in intraluminal diameter in 12 patients with PTA decreased from a mean of $84 \%$ to a mean of $44 \%$ after angioplasty. The mean follow up period in 11 patients, who survived more than six months, was 24 months. Clinically there was complete resolution of posterior circulation ischaemia and there were no further episodes of posterior circulation stroke in the 11 patients with long term follow up except one patient who had transient ischaemic attack and recurrent restenosis. This patient is now controlled by medical treatment only. Restenosis occurred in two patients (17\%). In one patient the distal vertebral artery was involved, and in the second, the midbasilar artery.

A total of four complications occurred. Two patients had acute arterial dissection due to the angioplasty procedure, leading to abrupt total occlusion. One led to a brain stem infarction and the patient died 48 hours after the procedure. The second patient (6) had an infarction of the cerebellum and occipital lobe. This patient was left with a permanent deficit. Two patients experienced thromboembolic complications. Two patients showed transient neurological deficits. Except for infarctions due to arterial dissection, all other infarctions were thought to be due to occlusion of perforators to the brain stem.

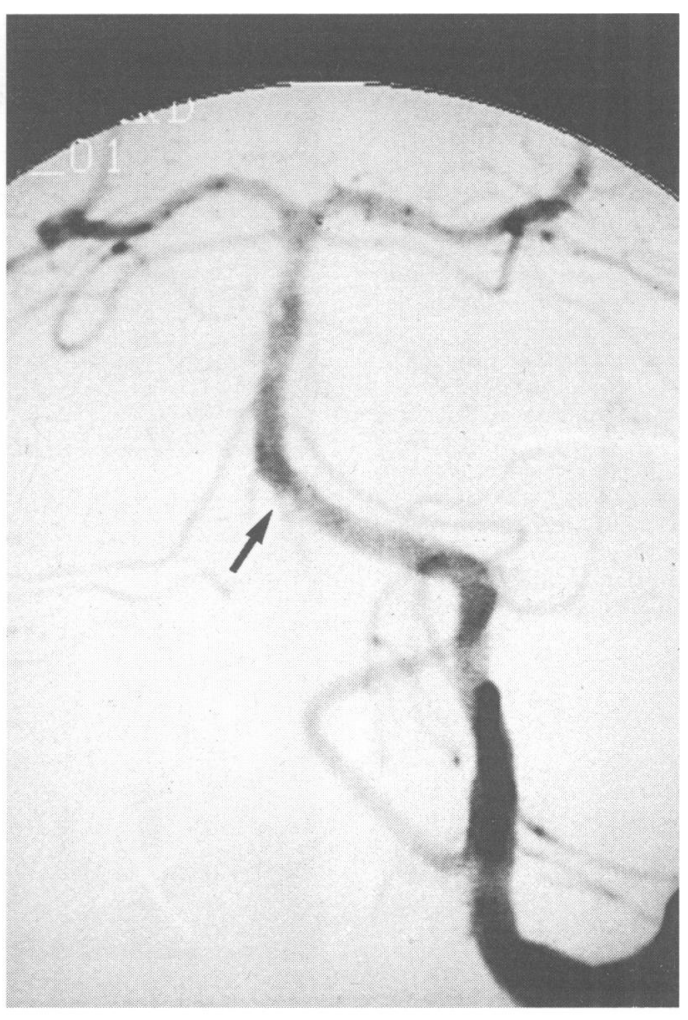

$B$

Overall, therefore, there were two major complications with one death and one permanent neurological deficit (17\%).

\section{Illustrative cases}

PATIENT 5: DISTAL VERTEBRAL ARTERY ANGIOPLASTY

A 66 year old man presented with the sudden onset of vertigo, nausea, vomiting, and unsteady gait. Brain MRI disclosed a right cerebellar infarction. Cerebral angiography showed complete occlusion of the right vertebral artery and a high grade stenosis of greater than $90 \%$ involving the left distal vertebral artery (fig 1A). A $3.0 \mathrm{~mm}$ balloon dilatation catheter was navigated across the stenosis via a transfemoral arterial approach. Successful dilatation of the stenosis was performed for 10 seconds, three times, and the balloon was rapidly deflated.

The postangioplasty arteriogram showed wide patency at the angioplasty site, with excellent blood flow to the distal posterior circulation. A transient gaze palsy and mild weakness of the left side of his body appeared immediately after the angioplasty procedure and he was given intravenous heparin. The symptoms completely resolved within 48 hours. His follow up angiogram showed improved luminal diameter and he was discharged on warfarin (4 mg alternated with $5 \mathrm{mg}$ every day). The follow up arteriogram two months later showed a widely patent vertebral artery with $100 \%$ patency at the angioplasty site. (fig 1B) At 19 months of clinical follow up the patient's symptoms of vertebrobasilar ischaemia has not recurred and the patient remained clinically and neurologically stable. 
Figure 2 Right vertebral angiogram of patient 12 . (A) Right vertebral angiogram before PTA; there is a high grade stenosis involving the distal right vertebral artery at the $C 1$ level (arrow).

(B) Right vertebral angiogram after the initial $P T A$; there is moderate dilatation at the angioplasty site (arrow). (C) Right vertebral angiogram six months after the initial PTA; there is restenosis at the angioplasty site (arrow). (D) Right vertebral angiogram after second PTA; the stenotic portion is now dilated to 70\% patency (arrow).

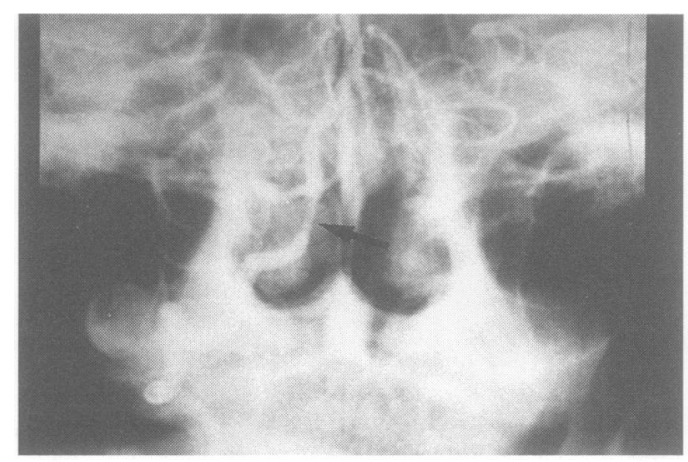

A

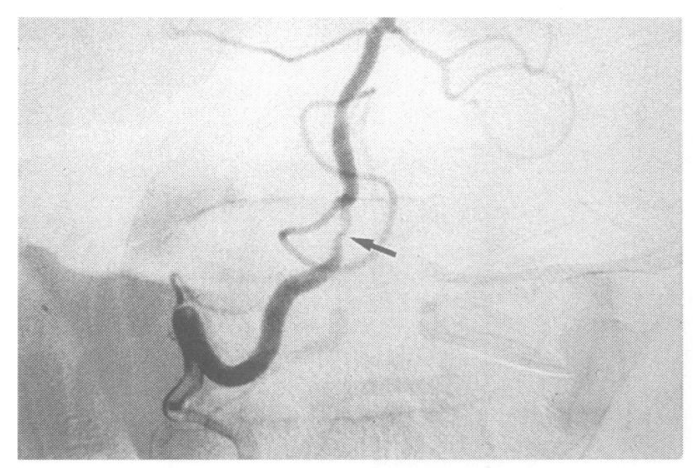

C

PATIENT 11: RESTENOSIS AFTER DISTAL VERTEBRAL ANGIOPLASTY

A 66 year old man was admitted with disturbance of consciousness, left ataxia, and fluctuating tetraparesis. Antiplatelet therapy with ticlopidine (200 mg/day) was started. Brain MRI showed a small high intensity area in the left cerebral peduncle and cerebellar hemisphere three weeks after the onset of his initial symptoms. Cerebral arteriography showed a left vertebral artery occlusion and a high grade stenosis of the right vertebral artery (fig $2 \mathrm{~A}$ ). 99m Tc-HM-PAO SPECT showed a low perfusion area with poor vascular reactivity for the diamox challenge involving the entire posterior fossa. He was alert and had left ataxia and mild right hemiparesis on the fourth week. A PTA of his stenotic right vertebral artery was performed on the 28 th day after his stroke.

A $3.0 \mathrm{~mm}$ balloon catheter was navigated across the stenosis via a transfemoral arterial approach. Angioplasty was performed twice for 90 and 120 seconds respectively. The stenosis was reduced angiographically from $80 \%$ to $60 \%$ (fig $2 \mathrm{~B}$ ). A follow up angiogram six months after the initial angioplasty however, showed restenosis (fig 2C).

A second PTA was performed using a 3.0 mm balloon, without any complication and resulted in successful dilatation (fig 2D). However, a follow up angiogram three months after the second procedure again showed restenosis. Clinically the patient remains asymptomatic without further symptoms of vertebral basilar ischaemia on medical therapy.

\section{Discussion}

Direct exposure with intraoperative angioplasty of the vertebrobasilar artery was initially performed in the early $1980 \mathrm{~s}^{7}$; however the

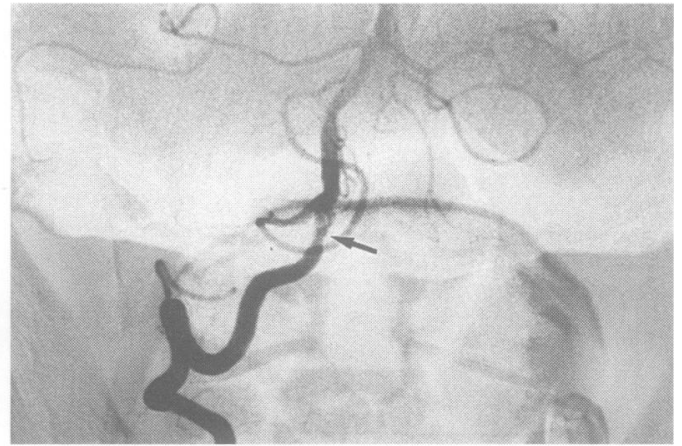

B

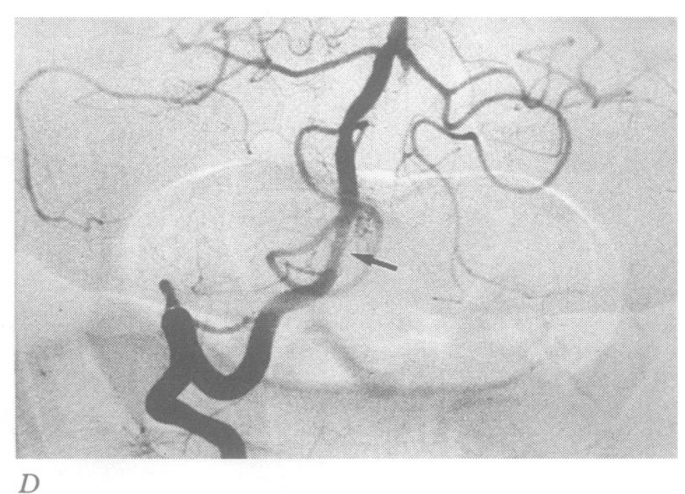

results were not satisfactory. We also performed this procedure in two patients previously but it was also unsatisfactory, and we abandoned it. The failures were due to the stiffness of the balloon catheters, which caused major complications of vessel rupture and dissection. Recent technological improvements in compliant balloon catheter systems, microguide wires, and flexible microcatheters for introduction have now made angioplasty of intracranial stenotic lesions feasible. ${ }^{811}$ Several reports have described successful results of PTA for intracranial arteries ${ }^{811-13}$ but there are no reports involving large numbers of patients, although PTA for supra-aortic arteries, including the proximal vertebral artery and extracranial internal carotid artery, has been reported with low complication rates. ${ }^{15} 16$

Acute basilar artery and bilateral vertebral artery stenosis or occlusion is associated with high mortality and serious neurological deficits. Conventional medical treatment usually consists of anticoagulation or antiplatelet drugs. $^{217}$ For patients with stenosis of both vertebral arteries, severe narrowing of the basilar artery, or long segment stenosis with irregularity and evidence of posterior fossa ischaemia, PTA may be a viable alternative to improve blood flow to the posterior circulation and to decrease the risk of acute occlusion and thromboembolic complications. The potential complications associated with distal vertebral and basilar artery angioplasty include vessel dissection, vessel rupture, and thromboemboli from disruption of the atheromatous plaque. To prevent ischaemic complications resulting from acute arterial dissection and abrupt closure, leaving an exchange guide wire across the lesion is essential to provide access for further angioplasty, until the successful opening is confirmed after the angioplasty. Vessel rup- 
ture may be decreased by using an appropriately sized balloon, which is not larger than the normal luminal diameter.

Other complications which might result from angioplasty are due to occlusion of the perforating arteries. The multiple small brain stem perforating arteries that arise from the distal vertebral and basilar artery provide blood to the proximal spinal cord, brain stem, hypothalamus, and thalamus. Therefore, occlusion of the small perforating artery often causes serious neurological deficits as seen in two of our patients $(6,10)$. This complication is difficult to avoid, because angioplasty of an atheromatous plaque results in intimal and medial disruption with associated damage to adjacent small arteries. Therefore, PTA of the distal vertebral and basilar artery should be performed only in cases of severe stenosis (more than $70 \%)^{14}$ that are refractory to medical treatment.

The natural history of vertebral and basilar artery stenosis of more than $70 \%$ is not completely known. ${ }^{12}$ However, the rate of reinfarction could be high as the North American Symptomatic Carotid Endarterectomy Trial ${ }^{14}$ has shown that at two years, the risk of an ipsilateral stroke for patients with an internal carotid arterial stenosis greater than $70 \%$, and only treated medically is $26 \%$.

We encountered two patients with restenosis within six months from the seven patients that had angiographic follow up. This rate is similar to the number reported for coronary PTA series. ${ }^{18-20}$ Some drugs, such as calcium antagonists or angiotensin converting enzyme inhibitors, ${ }^{21-23}$ were thought to prevent restenosis but the effect of these drugs is still not clearly defined. If restenosis does occur, then a repeat angioplasty procedure can be performed.

\section{Conclusion}

Acute occlusion or high grade stenosis of major vessels involving the posterior cerebral circulation is associated with high morbidity and mortality. Cerebral percutaneous transluminal angioplasty of the distal vertebral and basilar artery for haemodynamically significant lesions is now technically feasible. In symptomatic patients who are not adequately managed by conventional medical treatment, angioplasty is a viable alternative. Further studies and trials are warranted to confirm angioplasty as clinically efficacious for treating symptomatic stenosis of the intracranial blood vessels.

1 Archer CT, Horenstein S. Basilar artery occlusion. Clinical and radiological correlation. Stroke 1977;8:383-7.

2 Weksler BB, Lewin M. Anticoagulation in cerebral ischemia. Stroke 1983;14:658-63.

3 Fisher CM. Bilateral occlusion of basilar artery branches. $\mathcal{F}$ Neurol Neurosurg Psychiatry 1977;40:1182-9.

4 Ausman JI, Nicoloff DM, Chou SN. Posterior fossa revascularization: anastomosis of vertebral artery to PICA with interposed radial artery graft. Surg Neurol 1978; 9:281-86.

5 Ausman JI, Lee MC, Chater NC, et al. Superficial temporal to superior cerebellar artery anastomosis for distal basilar artery stenosis. Surg Neurol 1979;12:277-82.

6 Hopkins LN, Budny JL. Complications of intracranial bypass for vertebrobasilar insufficiency. $f$ Neurosurg 1989;70:207-11.

7 Sundt TM Jr, Smith HC, Campbell JK, et al. Transluminal angioplasty for basilar artery stenosis. Mayo Clin Proc 1980;55:673-80.

8 Higashida RT, Hieshima GB, Tsai FY, et al. Transluminal angioplasty of the vertebral and basilar artery. AfNR $A m \mathcal{F}$ Neuroradiol 1987;8:745-9.

9 Theron J, Courtheoux P, Henriet JP, et al. Angioplasty of supraaortic arteries. $\mathcal{F}$ Neuroradiol 1984;11:187-200.

10 Tsai FY, Matovich V, Hieshima GB, et al. Percutaneous transluminal angioplasty of the carotid artery. AfNR Am $\mathcal{F}$ Neuroradiol 1986;7:349-58.

11 Ahuj A, Guterman LR, Hopkins LN. Angioplasty for basilar artery atherosclerosis. Case report. $\mathcal{F}$ Neurosurg 1992; 77:941-4

12 Higashida RT, Tsai FY, Halbach VV, et al. Transluminal angioplasty for atherosclerotic disease of the vertebral and basilar arteries. $\mathcal{F}$ Neurosurg 1993;78:192-8.

13 Tsai FY, Berberian B, Matvich V, Lavin M, Alfieri K Percutaneous transluminal angioplasty adjunct to thrombolysis for acute middle cerebral artery rethrombosis. AFNR Am f Neuroradiol 1994;15:1823-9.

14 North American Symptomatic Carotid Endarterectomy Trial Collaborators. Beneficial effect of carotid endarterectomy in symptomatic patients with high grade endarterectomy in symptomatic patients with high

15 Brown MM, Butler P, Gibbs J, Swash M, Waterston J. Feasibility of percutaneous transluminal angioplasty for carotid artery stenosis. F Neurol Neurosurg Psychiatry 1990;53:238-43.

16 Kachel R, Basche ST, Heerklotz I, Grossman K, Endler S. Percutaneous transluminal angioplasty (PTA) of supraaortic arteries especially the internal carotid artery. Neuroradiol 1991;33:191-4.

17 Garde A, Samuelsson K, Fahlgren H, et al. Treatment after transient ischemic attacks: a comparison between anticoagulant drug and inhibition of platelet aggregation. Stroke 1983;14:677-81.

18 Bauters C, McFadden EP, Lablanche JM, Quandalle P, Bertland ME. Restenosis rate after multiple percutaneous coronary angioplasty procedures at the same site. A quantitative angiographic study in consecutive patients quantitative angiographic study in consecutive patients undergoing a third angioplasty procedur

19 DiSciascio G, Veterovec GW, Lewis SA, Nath A, Cole SK, Edward VL. Clinical and angiographic recurrence following PTCA for nonacute occlusions: comparison of oneversus five-minute inflation's. Am Heart $f$ 1990;120: 529-32.

20 Kirigaya $\mathrm{H}$, Aizawa $\mathrm{T}$, Ogasawara $\mathrm{K}$, et al. Incidence of acetylcholine-induced spasm of coronary arteries subjected to balloon angioplasty. Fpn Circ f 1993;57:883-90

21 Casscells W, Lappi DA, Olwin BB, et al. Elimination of smooth muscle cells in experimental restenosis: targeting of fibroblast cells in experimental restenosis: targeting USA 1992;89:7159-63.

22 Lam JY, Lacoste L, Bourassa MG. Cilazapril and early atherosclerotic changes after balloon injury of porcine crosclerotic changes after balloon injury

23 Rogers C, Karnovsky MJ, Edelman ER. Inhibition of experimental neointimal hyperplasia and thrombosis depends on the type of vascular injury and the site of drug administration. Circulation 1993;88:1215-21. 